\title{
Pengaruh Kepemimpinan Dan Motivasi Kerja Terhadap Produktivitas Kerja Karyawan PT Pegadaian (Persero) Cabang Sila Bolo Kabupaten Bima
}

\section{The Influence of Leadership and Work Motivation on Employee Productivity of PT Pegadaian (Persero) Sila Bolo Branch, Bima Regency}

\author{
Ibrahim $^{1}$ M. Badar ${ }^{2}$ \\ Manajemen, Sekolah Tinggi Ilmu Eknomi Bima \\ ${ }^{1}$ ibrahimbk05mangge@gmail.com \\ ${ }^{2}$ muhammadbadar.stiebima@gmail.com
}

\begin{abstract}
ABSTRAK
Perusahaan sangat membutuhkan karyawan yang mempunyai produktivitas tinggi karna karyawan pada hakekatnya merupakan salah satu unsur yang menjadi sumber daya dalam perusahaan, sumber daya manusia inilh yang menjalankan kegiatan sehari-hari. Untuk mewujudkan karyawan yang mempunyai produktivitas yang tinggi perlu kepemimpinan yang baik dari atas dan juga motivasi kerja dari karyawannya. Penelitian ini bertujuan untuk mengetahui pengaruh kepemimpinan dan motivasi kerja terhadap kerja karyawan PT. Pegadaian Cabang Sila Kabupaten Bima. Peneitian ini berjenis asosiatif dengan jenis data kuantitatif dari sumber data primer. Populasi yang digunakan dalam penelitian ini yaitu seluruh karyawan PT Pegadaian (Persero) Cabang Sila Bolo Kabupaten Bima sebanyak 30 orang karyawan dengan rincian pegawai sebanyak 30 orang pegawai tetap dan 8 orang pegawai kontrak. Teknik sampling yang digunakan yaitu teknik sampling jenuh, sehingga sampel yang digunakan adalah 30 orang pegawai tetap sebanyak 30 orang responden. Teknik analisa data yang digunakan adalah uji validitas, uji reliabilitas, uji asumsi klasik, analisis regresi, korelasi, uji determinasi, uji t dan uji f. Berdasarkan hasil uji t menunjukan secara parsial bahwa terdapat pengaruh variabel Kepimpinan terhadap Produktivitas Kerja karyawan PT. Pegadaian (Persero) Cabang Sila Bolo Kabupaten Bima, sedangkan variabel Motivasi Kerja tidak berpengaruh terhadap Produktivitas Kerja karyawan PT. Pegadaian (Persero) Cabang Sila Bolo Kabupaten Bima. berdasrkan hasil uji f menunjukan bahwa kepimpinan dan motivasi kerja secara bersama-sama berpengaruh terhadap produktivitas kerja karyawan PT. Pegadaian (Persero) Cabang Sila Bolo Kabupaten Bima.
\end{abstract}

Keywords: Kepemimpinan, Motivasi Kerja, Produktivitas Kerja

\begin{abstract}
Companies really need employees who have high productivity because employees are essentially one of the elements that become a resource in the company, these human resources who carry out daily activities. To realize employees who have high productivity need good leadership from above and also work motivation from their employees. This study aims to determine the effect of leadership and work motivation on the work of employees of PT. Pegadaian Sila Branch, Bima Regency. This research is an associative type with quantitative data from primary data sources. The population used in this study were all employees of PT Pegadaian (Persero) Cabang Sila Bolo, Bima Regency as many as 30 employees with the details of employees as many as 30 permanent employees and 8 contract employees. The sampling technique used is saturated sampling technique, so the sample used is 30 permanent employees as many as 30 respondents. The data analysis technique used is validity test, reliability test, classical assumption test, regression analysis, correlation, determination test, $t$ test and f test. Based on the results of the t test, it shows partially that there is an influence of the leadership variable on the work productivity of the employees of PT. Pegadaian (Persero) Cabang Sila Bolo, Bima Regency, while the Work Motivation variable had no effect on the Work Productivity of PT. Pegadaian (Persero) Sila Bolo Branch, Bima Regency. based on the results of the $f$ test shows that leadership and work motivation together have an effect on the work productivity of the employees of PT. Pegadaian (Persero) Sila Bolo Branch, Bima Regency.
\end{abstract}

Keywords: Leadership, Work Motivation, Work Productivity 


\section{PENDAHULUAN}

Perusahaan sangat membutuhkan karyawan yang mempunyai produktivitas tinggi karna karyawan pada hakekatnya merupakan salah satu unsur yang menjadi sumber daya dalam perusahaan, sumber daya manusia inilh yang menjalankan kegiatan sehari-hari. Menurut Sudria munawar dalam Zebua (2017), Produktivitas kerja adalah hasil kerja dalam satu waktu pada total organisasi produksi. Produktivitas kerja karyawan menjadi tolak ukur keberhasilan perusahaan, dengan meningkatkan produktivitas kerja diharapkan akan tercapainya tujuan dari organisasi serta dapat meningkatkan kualitas barang atau jasa yang dihasilkan oleh perusahaan tersebut.

Faktor yang mempengaruhi produktivitas kerja karyawan salah satunya adalah kepemimpinan yang dimilki oleh pemimpin dalam suatu organisasi aatau instansi, setiap manusia mempunyai watak dan perilaku yang berbeda. Menurut Yukl dalam Zebua (2017), Kepemimpinan ialah proses yang disengaja dari seseorang untuk menekankan pengaruhnya yang kuat terhadap orang lain untuk membimbing, membuat struktur, memfasilitasi aktivitas dan hubungan dalam kelompok atau organisasi. Hal itulah yang mendasari adanya perbedaan antara pemimpin satu dengan yang lain dalam menjadi pemimpinan diperusahaannya.

Kepemimpinan yang dimiliki oleh seseorang akan berpengaruh terhadap kelancaran kegiatan kerja. Seorang pemimpin yang disukai karyawannya, jika dalam penerapan kepemimpinannya dapat mengerti dan memahami keinginan serta kebutuhan bawahannya, sehingga dengan kepemimpinannya tersebut dapat digunakan untuk mempengaruhi bawahan dalam berbagai hal, baik di dalam perusahaan maupun di luar perusahaan.

Untuk mewujudkan karyawan yang mempunyai produktivitas yang tinggi juga perlu adanya motivasi kerja. Motivasi ialah pemberian daya gerak yang menciptakan keinginan kerja seseorang agar mereka mau bekerja sama, bekerja efektif degan segala daya dan upaya untuk mencapai tujuan yang di kehendaki. Menurut Newstrom dalam Laksmiari (2019), motivasi kerja adalah kesediaan individu untuk mengeluarkan upaya yang tinggi untuk mencapai tujuan organisasi.

Pemberian motivasi sangat penting dalam setiap organisasi, pegawai yang memiliki motivasi kerja yang tinggi akan dapat mendorong dirinya sendiri untuk bekerja lebih giat dan bertanggung jawab dalam melakukan pekerjaanya. Motivasi timbul dengan adanya beberapa kebutuhan yang tidak terpenuhi sehingga menimbulkan tekanan atau rasa ketidakpuasan tersendiri sehingga mendorong terciptanya produktivitas kerja karyawan yang tinggi.

Pegadaian adalah sebuah badan usaha milik negara (BUMN) sektor keuangan Indonesia yang bergerak pada tiga lini bisnis perusahaan yaitu pembiayaan, emas dan aneka jasa.Layanan pembiayaan pegadaian meliputi : Kredit, cepat dan aman (KCA), Kredit angsuran fidusia (Kreasi) dan Kredit angsuran sistem gadai (Krasida). sedangkan Layanan emas meliputi : Mulia dan Tabungan emas.

Pada observasi awal yang telah dilakukan peneliti pada PT. Pegadaian (Persero) Cabang Sila Bolo Kabupaten Bima dengan mewawancarai beberapa karyawan disana, permasalahan yang ada pada PT. Pegadaian (Persero) Cabang Sila Bolo Kabupaten Bima yang berkaitan dengan kepemimpinan yaitu pimpinan yang dirasa kurang fleksibel dalam hal pemberian jam kerja bagi karyawan wanita yang sudah menikah dan mempunyai anak, pimpinan yang kurang mengapresiasi kinerja karyawannya meskipun sekedar memberikan pujian untuk pencapaian yang telah didapatkan oleh karyawannya. Permasalahan lain yang terlihat adalah bahwa masih adanya karyawan yang kurang termotivasi dalam bekerja, hal ini dibuktikan dengan adanya karyawan yang 
masih menunda-nunda pekerjaan pada saat jam kerja yang mengindikasikan kurangnya tanggung jawab karyawan atas pekerjaan yang telah dibebankan kepadanya, karyawan tidak tepat waktu saat datang bekerja sehinga membuat beban kerja yang akhirnya tertumpu pada sebagian karyawan yang lebih dahulu datang bekerja. Selain permasalahan pada kepemimpinan dan motivasi kerja, produktivitas kerja karyawan PT. Pegadaian (Persero) Cabang Sila Bolo Kabupaten Bima juga kurang optimal dimana karyawan masih kurang semangat dalam bekerja, ini disebakan rendahnya rasa tanggung jawab lebih karyawan terhadap hasil kerja yang ingin dicapai.

Dengan permasalahan diatas melatarbelakangi penulis ingin melakukan penelitian dengan judul "Pengaruh Kepemimpinan Dan Motivasi Kerja Terhadap Produktivitas Kerja Karyawan PT. Pegadaian Cabang Sila Kabupaten Bima".

\section{METODE}

Penelitian ini berjenis asosiatif, Populasi yang digunakan dalam penelitian ini yaitu seluruh karyawan PT Pegadaian (Persero) Cabang Sila Bolo Kabupaten Bima sebanyak 30 orang karyawan dengan rincian pegawai sebanyak 30 orang pegawai tetap dan 8 orang pegawai kontrak. Teknik sampling yang digunakan yaitu teknik sampling jenuh, sehingga sampel yang digunakan adalah 30 orang pegawai tetap sebanyak 30 orang responden. Instrumen penelitian yang digunakan dalam mengumpulkan data adalah kuesioner dengan skala likert yang diberi skor 1 sampai 5 .

Teknik pengumpulan data dilakukan oleh peneliti yaitu menggunakan observasi, kuesioner, dan studi pustaka, dengan menggunakan jenis data kuantitatif dari sumber data primer. Tekhnik analisis data yang digunakan yaitu, uji validitas, uji reliabilitas, uji asumsi klasik, analisis regresi berganda, korelasi berganda, uji determinasi, uji t dan uji f dengan bantuan SPSS for windows version 20.

\section{HASIL DAN PEMBAHASAN}

Berdasarkan hasil pengujian validitas dan reliabilitas kuesioner menunjukan bahwa kuesioner yang telah dibagina sudah valid dengan nilai validitas lebih dari standar 0,300, dan nilai reliabilitas sudah lebih dari standar nilai yaitu 0,600 . Hasil ini menunjukan bahwa kuesioner sudah layak untuk digunakan dalam penelitian ini.

\section{Uji Asumsi Klasik}

Uji Normalitas

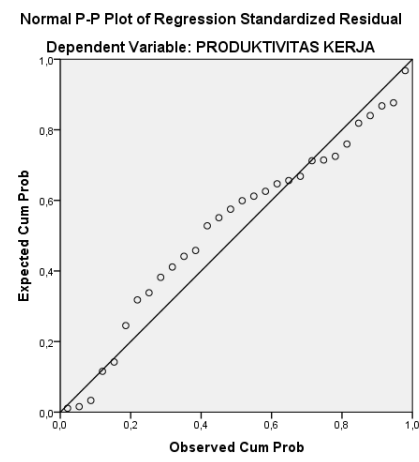

Gambar 1. Uji Normalitas

Sumber Data: Data primer diolah Spss v20 2021 
Gambar 1, di atas menunjukkan bahwa grafik Normal P-P of Regression Standardized Residual menggambarkan penyebaran data di sekitar garis diagonal dan penyebarannya mengikuti arah garis diagonal grafik tersebut, maka model regresi yang digunakan dalam penelitian ini memenuhi asumsi normalitas.

Untuk memperkuat pengujian normalitas, maka peneliti menambahkan uji kolmogorov-smirnov dengan hasilnya adalah sebagai berikut :

Tabel 3. Hasil Uji kolmogorov-smirnov

\begin{tabular}{|c|c|c|}
\hline \multicolumn{3}{|c|}{ One-Sample Kolmogorov-Smirnov Test } \\
\hline & & $\begin{array}{c}\text { Unstandard } \\
\text { ized } \\
\text { Residual }\end{array}$ \\
\hline $\mathrm{N}$ & & 30 \\
\hline \multirow[t]{3}{*}{ Normal Parameters $^{\mathrm{a}, \mathrm{b}}$} & Mean & 0E-7 \\
\hline & Std. & 2,9612381 \\
\hline & Deviation & 5 \\
\hline \multirow{3}{*}{$\begin{array}{l}\text { Most Extreme } \\
\text { Differences }\end{array}$} & Absolute & ,129 \\
\hline & Positive &, 082 \\
\hline & Negative &,- 129 \\
\hline \multicolumn{2}{|l|}{ Kolmogorov-Smirnov Z } & ,706 \\
\hline \multicolumn{2}{|l|}{ Asymp. Sig. (2-tailed) } & ,701 \\
\hline \multicolumn{3}{|c|}{ a. Test distribution is Normal. } \\
\hline \multicolumn{3}{|l|}{ b. Calculated from data. } \\
\hline
\end{tabular}

Sumber : Data primer diolah Spss v20 2021

Berdasarkan hasil uji kolmogorofSmirnov di atas, terlihat nilai Asymp.Sig memiliki nilai $>0.05$ yaitu sebesar 0,701 . Hal ini menunjukkan bahwa data pada penelitian ini terdistribusi secara normal dan model regresi tersebut layak dipakai untuk memprediksi variabel dependen yaitu Produktivitas Kerja berdasarkan masukan variabel independen yaitu Kepemimpinan dan Motivasi Kerja. Maka data penelitian layak digunakan sebagai penelitian.

Uji Multikolinearitas

Tabel 4. Hasil Uji Multikolinearitas

\begin{tabular}{|c|c|c|c|}
\hline \multicolumn{4}{|c|}{ Coefficients $^{\mathrm{a}}$} \\
\hline \multicolumn{2}{|c|}{ Model } & \multicolumn{2}{|c|}{$\begin{array}{c}\text { Collinearity } \\
\text { Statistics }\end{array}$} \\
\hline & & $\begin{array}{c}\text { Toleran } \\
\text { ce }\end{array}$ & VIF \\
\hline \multirow[t]{2}{*}{1} & Kepemimpinan & ,665 & 1,504 \\
\hline & Motivasi Kerja & ,665 & 1,504 \\
\hline \multicolumn{4}{|c|}{ a. Dependent Variable: Produktivitas Kerja } \\
\hline
\end{tabular}


Berdasarkan nilai Collinearity Statistic dari output di atas, di peroleh nilai Tolerance variable Kepemimpinan (X1) dan Motivasi Kerja (X2) adalah > 0,10 sementara, nilai VIF untuk Kepemimpinan
(X1) dan Motivasi Kerja (X2) < 10.00. maka dapat di di simpulkan bahwa tidak

terjadi gejala multikolineritas dalam model regresi.

\section{Uji Heteroskedastisitas}

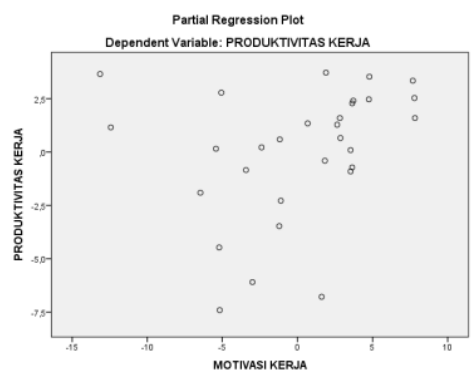

Gambar 2. Uji Heterokedastisistas

Sumber : Data primer diolah Spss v20 2021

Grafik Scatterplot yang ditampilkan untuk uji heterokesdastisitas menampakkan titik-titik yang menyebar secara acak dan tidak ada pola yang jelas terbentuk serta dalam penyebaran titik-titik tersebut menyebar dibawah dan diatas angka 0 pada sumbu Y. Hal tersebut mengidentifikasikan tidak terjadinya heterokesdastisitas pada model regresi, sehingga model regresi layak dipakai untuk memprediksi variabel Produktivitas $\operatorname{Kerja}(\mathrm{Y})$.

\section{Uji Autokorelasi}

Tabel 5. Hasil Uji Autokorelasi

\begin{tabular}{|c|c|c|c|c|c|}
\hline \multicolumn{6}{|c|}{ Model Summary ${ }^{b}$} \\
\hline $\begin{array}{l}\text { Mo } \\
\text { del }\end{array}$ & $\mathrm{R}$ & $\begin{array}{c}\mathrm{R} \\
\text { Square }\end{array}$ & $\begin{array}{c}\text { Adjusted R } \\
\text { Square }\end{array}$ & $\begin{array}{l}\text { Std. Error } \\
\text { of the } \\
\text { Estimate }\end{array}$ & $\begin{array}{l}\text { Durbin- } \\
\text { Watson }\end{array}$ \\
\hline 1 &, $803^{\mathrm{a}}$ &, 645 & ,618 & 3,069 & 1,888 \\
\hline \multicolumn{6}{|c|}{ A. Predictors: (Constant), Motivasi Kerja, Kepemimpinan } \\
\hline B. D & ident V & iable: $\operatorname{Pr}$ & uktivitas Kel & & \\
\hline
\end{tabular}

Di dalam uji Durbin Watson ini, harus memenuhi kriteria sebagai berikut :

Tabel 6. Kriteria Durbin Watson

\begin{tabular}{cc}
\hline $\begin{array}{c}\text { Kriteria Durbin } \\
\text { Watson }\end{array}$ & Keterangan \\
\hline $1,65<\mathrm{DW}<2,35$ & Tidak terjadi autokorelasi \\
\hline $1,21<\mathrm{DW}<1,65$ & Tidak dapat disimpulkan \\
\hline $2,35<\mathrm{DW}<2,79$ & Tidak dapat disimpulkan \\
\hline $\mathrm{DW}<1,21$ & Terjadi autokorelasi \\
\hline DW $>2,79$ & Terjadi autokorelasi \\
\hline
\end{tabular}

Sumber : Sulaiman, 2011:89 
Dari hasil olah data SPSS maka diperoleh nilai durbin watson sebesar 1,888. Nilai Durbin Watson ini memenuhi kriteria 1,65 < DW < 2,35, maka 1,65 < $1,888<2,35$ yang artinya tidak terjadi autokorelasi.

\section{Regresi Linear Berganda}

Tabel 7. Hasil Uji Regresi Linear Berganda

\begin{tabular}{|c|c|c|c|c|c|}
\hline \multicolumn{6}{|c|}{ Coefficients $^{\mathrm{a}}$} \\
\hline \multirow[t]{3}{*}{ Model } & \multirow{2}{*}{\multicolumn{2}{|c|}{$\begin{array}{c}\text { Unstandardized } \\
\text { Coefficients }\end{array}$}} & \multirow{3}{*}{$\begin{array}{c}\text { Standardized } \\
\text { Coefficients } \\
\text { Beta }\end{array}$} & \multirow[t]{3}{*}{$\mathrm{t}$} & \multirow[t]{3}{*}{ Sig. } \\
\hline & & & & & \\
\hline & $\mathrm{B}$ & Std. Error & & & \\
\hline (Constant) & 1,637 & 5,407 & & ,303 & ,764 \\
\hline Kepemimpinan & ,904 & , 190 & ,669 & 4,753 &, 000 \\
\hline Motivasi Kerja &, 153 &, 106 & ,203 & 1,440 & ,161 \\
\hline a. Dependent Variab & ktivitas & erja & & & \\
\hline
\end{tabular}

Dari hasil analisis regresi dapat diketahui persamaan regresi berganda sebagai berikut:

$$
\mathrm{Y}=1,637+0,904 \mathrm{X} 1+0,153 \mathrm{X} 2
$$

Berdasarkan persamaan tersebut, maka dapat dijelaskan sebagai berikut:

a. Nilai konstanta sebesar 1,637 dapat diartikan apabila variabel Kepemimpinan dan Motivasi Kerja dianggap nol, maka Produktivitas Kerja akan sebesar 1,637.

b. Nilai koefisien beta pada variable Kepemimpinan sebesar 0,904 artinya setiap perubahan variabel Kepemimpinan (X1) sebesar satu satuan, maka akan mengakibatkan
Hasil uji autokolerasi diatas menunjukkan nilai statistik Durbin Watson sebesar 1,686 maka disimpulkan bahwa tidak terjadi autokolerasi. perubahan Produktivitas Kerja karyawan sebesar 0,904 satuan, dengan asumsi-asumsi yang lain adalah tetap. Peningkatan satu satuan pada variabel Kepemimpinan akan meningkatkan Produktivitas Kerja sebesar 0,904 satuan.

c. Nilai koefisien beta pada variabel Motivasi Kerja sebesar 0,153 artinya setiap perubahan variabel Motivasi Kerja (X2) sebesar satu satuan, maka akan mengakibatkan perubahan Produktivitas Kerja sebesar 0,153 satuan, dengan asumsi-asumsi yang lain adalah tetap. Peningkatan satu satuan pada variabel Motivasi Kerja akan meningkatkan Produktivitas Kerja sebesar 0,153 satuan. 


\section{Koefisein Kolerasi dan Uji Determinasi}

\section{Koefisien Korelasi}

Tabel 8. Hasil Uji Koefisien Kolerasi dan Uji Determinasi

\begin{tabular}{ccrrr}
\hline \multicolumn{5}{c}{ Model Summary } \\
\hline $\begin{array}{l}\text { Mo } \\
\text { del }\end{array}$ & $\mathrm{R}$ & $\begin{array}{c}\mathrm{R} \\
\text { Square }\end{array}$ & $\begin{array}{c}\text { Adjusted R } \\
\text { Square }\end{array}$ & $\begin{array}{c}\text { Std. Error } \\
\text { of the } \\
\text { Estimate }\end{array}$ \\
\hline 1 &, $803^{\mathrm{a}}$ &, 645 &, 618 & 3,069 \\
\hline
\end{tabular}

a. Predictors: (Constant), Motivasi Kerja, Kepemimpinan

\section{Sumber :Data Primer Diolah SPSS v20, 2021}

Dari hasil tersebut dapat diperoleh nilai $\mathrm{R}$ Square adalah sebesar 0,645 . Hasil tersebut menjelaskan bahwa terdapat pengaruh antara Kepemimpinan dan Motivasi Kerja terhadap Produktivitas
Kerja. Untuk dapat memberi interpretasi terhadap kuatnya pengaruh itu maka dapat digunakan pedoman seperti pada tabel berikut :

Tabel 9. Pembanding Tingkat Hubungan Koefisien Korelasi

\begin{tabular}{cc}
\hline $\begin{array}{c}\text { Interval } \\
\text { Koofisien }\end{array}$ & Tingkat Hubungan \\
\hline $0,00-0,199$ & Sangat Rendah \\
$0,20-0,399$ & Rendah \\
$0,40-0,599$ & Sedang \\
$0,60-0,799$ & Kuat \\
$0,80-1,000$ & Sangat Kuat
\end{tabular}

\section{Sumber : Sugiyono 2016 \\ Jadi kolerasi hubungan}

Kepemimpinan dan Motivasi Kerja terhadap Produktivitas Kerja sebesar 0,645 berada pada interval $0,60-0,799$ dengan tingkat hubungan kuat.

\section{Uji Determinasi}

Pada tabel di atas juga diketahui bahwa nilai Adjusted $R$ Square sebesar
0,618, Jadi terdapat pengaruh antara Kepemimpinan dan Motivasi Kerja terhadap Produktivitas Kerja yang besarnya pengaruh tersebut sebesar 0,618 atau $61,8 \%$, sedangkan sisanya $38,2 \%$ dipengaruhi oleh faktor lain yang tidak diteliti dalam penelitian ini. 


\section{Hasil Uji f}

Tabel 10. Hasil Uji f

\begin{tabular}{llccrrr}
\hline \multicolumn{7}{c}{ ANOVA $^{\text {a }}$} \\
\hline Model & $\begin{array}{l}\text { Sum of } \\
\text { Squares }\end{array}$ & Df & $\begin{array}{c}\text { Mean } \\
\text { Square }\end{array}$ & F & Sig. \\
\hline 1 & $\begin{array}{l}\text { Regressi } \\
\text { on }\end{array}$ & 461,568 & 2 & 230,784 & 24,50 &, $000^{\text {b }}$ \\
\cline { 2 - 6 } & Residual & 254,299 & 27 & 9,418 & & \\
\cline { 2 - 6 } & Total & 715,867 & 29 & & & \\
\hline A. Dependent Variable: Produktivitas Kerja & & & \\
\hline B. Predictors: (Constant), Motivasi Kerja, Kepemimpinan \\
\hline \multicolumn{5}{l}{ Sumber :Data Primer Diolah SPSS v20, 2021 }
\end{tabular}

H3 : Kepimpinan dan Motivasi Kerja secara simultan berpengaruh terhadap Produktivitas Kerja karyawan PT. Pegadaian (Persero) Cabang Sila Bolo Kabupaten Bima

Dari hasil pengujian diperoleh nilai Fhitung sebesar 24,503 dengan nilai Ftabel sebesar 2,95 $(24,503>2,95)$ dengan signifikansi sebesar $0,000(0,000<0,05)$. Oleh karena nilai signifikansi lebih kecil dari $0,05(0,000<0,05)$, maka dapat disimpulkan bahwa hipotesis ketiga yang menyatakan bahwa "Kepimpinan dan Motivasi Kerja secara simultan berpengaruh terhadap Produktivitas Kerja karyawan PT. Pegadaian (Persero) Cabang Sila Bolo Kabupaten Bima” Diterima.

Penelitian ini sama seperti penelitian yang dilakukan oleh Harimisa (2013), menyatakan bahwa variabel Kepemimpinan dan Motivasi kerja secara simultan berpengaruh terhadap Produktivitas Kerja pegawai di Kantor Camat Sario Kota Manado PT. Sinar Sosro Kantor Penjualan (Kp) Pamanukan, ini mengindikasikan produktivitas kerja karyawan kemungkinan berubah bila terjadi perubahan pada kepemimpinan dan motivasi kerja.

\section{Hasil Uji t}

Tabel 11. Hasil Uji t

\begin{tabular}{ccc}
\hline \multicolumn{4}{c}{ Coefficients $^{\mathbf{a}}$} \\
\hline Model & $\mathrm{T}$ & Sig. \\
\hline (Constant) &, 303 & \multicolumn{2}{c}{, 764} \\
\hline Kepemimpinan & 4,753 &, 000 \\
\hline Motivasi Kerja & 1,440 &, 161 \\
\hline
\end{tabular}

A. Dependent Variable: Produktivitas Kerja

Sumber :Data Primer Diolah SPSS v20, 2021

H1 : Kepimpinan berpengaruh parsial terhadap Produktivitas Kerja karyawan PT. Pegadaian (Persero) Cabang Sila Bolo Kabupaten Bima

Hasil statistik uji t untuk variable Kepemimpinan diperoleh nilai thitung sebesar 4,753 lebih besar dari pada nilai $\mathrm{t}$ tabel sebesar 2,048 (4,753 > 2,048) dengan nilai signifikansi sebesar 0,000 lebih kecil dari $0,05(0,000<0,05)$, maka hipotesis pertama yang menyatakan bahwa "Kepimpinan berpengaruh parsial terhadap 
Produktivitas Kerja karyawan PT. Pegadaian (Persero) Cabang Sila Bolo Kabupaten Bima" Diterima. .Hal ini penting karna Hubungan antara modal manusia dan pertumbuhan ekonomi (Rabie, 2019)

Penelitian ini sama seperti penelitian yang dilakukan oleh Suryani, et al (2020), yang menyatakan bahwa variabel Kepemimpinan berpengaruh parsial terhadap Produktivitas Kerja Karyawan Produksi di PT tuntex Germen Indonesia.

H2 : Motivasi Kerja berpengaruh parsial terhadap Produktivitas Kerja karyawan PT. Pegadaian (Persero) Cabang Sila Bolo Kabupaten Bima

Hasil statistik uji t untuk variabel Motivasi Kerja diperoleh nilai thitung sebesar 1,440 lebih kecil dari pada nilai ttabel sebesar 2,048 (1,440<2,048) dengan nilai signifikansi sebesar 0,161 lebih besar dari $0,05(0,161<0,05)$ maka hipotesis kedua yang menyatakan bahwa "Motivasi Kerja berpengaruh parsial terhadap Produktivitas Kerja karyawan PT. Pegadaian (Persero) Cabang Sila Bolo Kabupaten Bima" Ditolak.

Penelitian ini sama seperti penelitian yang dilakukan oleh Rampisela dan Lumintang (2020), menyatakan bahwa variabel Motivasi Kerja tidak berpengaruh parsial terhadap Produktivitas Kerja Karyawan PT. Dayana Cipta.

\section{KESIMPULAN DAN SARAN Kesimpulan}

Berdasarkan pembahasan dari hasil analisa yang telah dilakukan, maka peneliti menarik kesimpulan bahwa : Kepimpinan dan Motivasi Kerja secara bersama-sama berpengaruh terhadap Produktivitas Kerja karyawan PT. Pegadaian (Persero) Cabang Sila Bolo Kabupaten Bima. Secara parsial terdapat pengaruh variabel Kepimpinan terhadap Produktivitas Kerja karyawan PT. Pegadaian (Persero) Cabang Sila Bolo Kabupaten Bima, sedangkan variabel Motivasi Kerja tidak berpengaruh terhadap Produktivitas Kerja karyawan PT. Pegadaian (Persero) Cabang Sila Bolo Kabupaten Bima. ini menunjukan bahwa variabel Produktivitas Kerja dominan Berbeda halnya hasil penelitian kebutuhan fisiologis, penghargaan, berpengaruh positif terhadap aktualisasi diri terhadap kinerja pegawai (Suharwan, 2019)

\section{Saran}

Berdasarkan kesimpulan di atas, penulis menyarankan agar PT. Pegadaian (Persero) Cabang Sila Bolo Kabupaten Bima perlu meningkatkan kepemimpinan dari atasannya, sehingga mendorong karyawan akan lebih terbuka dan aktif dalam kegiatan organisasi, dengan terus memperbaiki kepemimpinan tersebut diharapkan dapat menjadi faktor pendorong karyawan untuk meningkatkan produktivitas kerja karyawan dalam bekerja dan melayani nasabah PT. Pegadaian (Persero) Cabang Sila Bolo Kabupaten Bima .

Selain itu penulis juga menyarankan agar ada penelitian lanjutan dengan mempertimbangkan variabel lain misalnya kompensasi, gaya kepemimpinan dan lainlain maupun dengan objek dan metode yang berbeda guna memvalidasi penelitian ini

\section{DAFTAR PUSTAKA}

Anoraga, P. 2014. Psikologi Kerja. Jakarta: PT Rineka Cipta.

Arikunto, Suharsimi. 2011. Prosedur Penelitian Suatu Pendekatan Praktek. Jakarta: Rineka Cipta.

Azwar, Saifuddin. 2016. Metode Penelitian. Yogyakarta : Pustaka Pelajar.

Danang, S. 2012. Manajemen Sumber Daya Manusia. Jakarta. PT. Buku.

Hamid, R. (2019). Analisis Pengaruh Motivasi Terhadap Kinerja Pegawai 
Rumah Sakit Angkatan Laut Jala Ammari Makassar. Economy Deposit Journal (E-DJ), 1(1), 49-54.

Harimisa, E.M.2013. Kepemimpinan Dan Motivasi Kerja Pengaruhnya Terhadap Produktivitas Kerja Pegawai Di Kantor Camat Sario Kota Manado PT. Sinar Sosro Kantor Penjualan (Kp) Pamanukan. Jurnal EMBA. Vol.1 No.4 Desember 2013, Hal. 2143-2154.

Hasibuan. 2011. Manajemen Sumber Daya Manusia. Jakarta. Bumi Aksara.

Laksmiari, P.P.N. 2019. Pengaruh Motivasi Kerja Terhadap Produktivitas Kerja Karyawan Pada Perusahaan Teh Bunga Teratai Di Desa Patemon Kecematan Serrit. Jurnal Pendidikan Ekonomi Undhiksa. Vol. 11, No. 1, Hal. 54-63.

Marwansyah. 2016. Manajemen Sumber Daya Manusia. Bandung: Alfabeta.

Pinder. 2014. Work Motivation : Theory, Issues And Apllications. Illionois:Scoff, Foresmen and Company.

Purnama,R.2018. Pengaruh Motivasi Kerja Terhadap Produktivitas Kerja Karyawan Pada Bagian Produksi CV, EKSILON Bandung. Jurnal Strategis. Volume 7, Nomor 14. September 2018 hal. 58-82

Rahmawati, D.2013 Pengaruh Motivasi Terhadap Produktivitas Kerja Karyawan PR Fajar Berlian Tulungagung. Jurnal Universitas Telunggung Bonorowo. Vol. 1, No. 1 tahun 2013 hal 1-16

Rampisela, J. A. V, Lumintang, G.G. 2020. Pengaruh Motivasi Kerja dan Upah Terhadap Produktivitas Kerja Karyawan PT. Dayana Cipta. Jurnal EMBA.Vol. 8, NO.1, Hal. 302-311.

Sugiyono. 2012. Metode Penelitian Kuantitatif, Kualitatif dan R\&D. bandung: Alfabeta.

Sugiyono. 2016. Metode Penelitian Kuantitatif Kualitatif dan R\&D. Bandung : Alfabeta

Suryani, P, Cahyono, Y, Utami, D.B. 2020. Pengaruh Motivasi Dan Gaya Kepemimpinan Terhadap Produktivitas Kerja Karyawan Produksi Di PT tuntex Germen Indonesia. Jurnal of Industry
Engineering Dan Manajemen Research. Vol. 1, No. 1 hal 70-82. 2020

Rabie, R., \& Elliyana, E. (2019). Human capital and economic growth in Indonesia. Journal of Contemporary Economic Studies, 4(01), 169-176.

Sutrisno, E.2016. Manajamen Sumber Daya Manusia. Cetakan ke-8. Kencana Pernada . Media Grup

suharwan, suharwan, almukarom, mukti, \& Hamid, R. (2019). Analisis Pengaruh Motivasi Terhadap Kinerja Pegawai Rumah Sakit Angkatan Laut Jala Ammari Makassar. Economy Deposit Journal (E-DJ), 1(1), 49-54.

Thoha,M. 2010. Kepemimpinan Dalam Manajemen. Jakarta : PT. Raja. Garfindo Persada.

Wahrudin, U. 2020. Pengaruh Kepemimpinan Dan Motivasi Kerja Terhadap Produktivitas Kerja Karyawan. Jurnal Al Amar. Vol.1 No.2, Maret 2020, Hal. 39-49.

Wijayanto. 2012. Pengantar Manajemen. PT.Gramedia Pustaka Utama, Jakarta.

Yusuf. B. 2016. Manajemen Sumber Daya Manusia,. Jakarta. PT. Raja. Grafindo Persada

Zebua. M. 2017. Pengaruh Gaya Kepemimpinan Terhadap Produktivitas Kerja Karyawan Pada PT. Coca-Cola Cabang Malang. Jurnal Media Mahardhika. Vol. 15, No. 3, Hal. 259-304 